\title{
Perancangan dan Pendampingan Pembangunan Gedung Panti Asuhan Muhammadiyah Ahmad Sudjari di Yogyakarta
}

\author{
Anita Widianti ${ }^{* 1}$, Mandiyo Priyo ${ }^{2}$, Jefri Pratama ${ }^{1}$ \\ ${ }^{1}$ Program Studi Teknik Sipil FT Universitas Muhammadiyah Yogyakarta \\ ${ }^{2}$ Program Profesi Insinyur FT Universitas Muhammadiyah Yogyakarta \\ *email: anitawidianti@umy.ac.id, Telp. 0274-387656 ext. 256
}

\begin{abstract}
ABSTRAK
Panti Asuhan Muhammadiyah Ahmad Sudjari yang berada di Dusun Jonggrangan, Jatimulyo, Girimulyo, Kulon Progo, Yogyakarta berdiri sejak tahun 2008. Ada 20 anak yang tinggal di tempat tersebut. Prasarana yang tersedia masih terbatas dengan kondisi yang masih sederhana dan kurang representatif. Untuk itu perlu adanya tambahan ruang tidur dan kamar mandi/WC, serta ruang tamu, ruang bersama, ruang kantor dan dapur. Tim Pengabdian kepada Masyarakat (PkM) dari Program Studi Teknik Sipil Universitas Muhammadiyah Yogyakarta berinisiatif melakukan pengabdian di tempat tersebut dengan tujuan untuk membantu mewujudkan tempat tinggal dan tempat belajar agama bagi anak-anak yang representatif dari segi keamanan dan kenyamanan. Kegiatan yang dilaksanakan selama 6 bulan ini meliputi proses perancangan struktur dan proses pelaksanaan pembangunannya. Dari kegiatan ini dihasilkan dokumen perancangan yang terdiri dari perhitungan struktur, desain gambar gedung dua lantai, dan Rencana Anggaran Biayanya. Tim PkM juga memberikan pendampingan selama proses pembangunan hingga terwujud gedung 2 lantai dengan luas 9,0x9,5 $\mathrm{m}^{2}$ setiap lantainya.
\end{abstract}

Kata kunci: Dokumen perancangan, gedung dua lantai, Panti Asuhan Muhammadiyah Ahmad Sudjari

\begin{abstract}
Ahmad Sudjari's Muhammadiyah Orphanage which located in Jonggrangan Hamlet, Jatimulyo, Girimulyo, Kulon Progo, Yogyakarta were established in 2008. Currently there are 20 students living in the orphanage. The available infrastructure is still limited with condition that is still simple and less representative. For this reason, it is necessary to have additional bedrooms and bathrooms/toilets for students as well as a living room, common room, office and kitchen. The Community Service Team of Civil Engineering Program Universitas Muhammadiyah Yogyakarta took the initiative to do the service in the place with the aim of helping the orphanage to create a new place for living and religious learning for the students with safety and comfort. The activities carried out for 6 months included the process of designing the structure and the process of implementing and monitoring the construction works. From this activity a design document was produced consisting of structural calculations, two-story building design drawings, and the Cost Budget Plan. The Community Service Team also provided assistance during the implementation to realized the 2-story building with area of $9.0 \times 9.5 \mathrm{~m}^{2}$ each floor.
\end{abstract}

Keywords: Ahmad Sudjari's Muhammadiyah Orphanage, design documents, 2-story building

\section{PENDAHULUAN}

Muhammadiyah adalah sebuah organisasi Islam yang besar di Indonesia dan semakin berkembang pesat seiring dengan perkembangan zaman (Rusydi, 2016). Anggotanya diperkirakan lebih dari 50 juta umat Islam. Banyak sekali amal usaha yang dimiliki oleh Muhammadiyah, baik di bidang keagamaan, bidang pendidikan maupun bidang sosial kemasyarakatan. Dalam bidang sosial kemasyarakatan diantaranya adalah mendirikan panti asuhan (Tahir, 2010). Panti asuhan merupakan sebuah lembaga sosial yang bertujuan untuk memberikan kesejahteraan bagi anak terlantar, yatim, piatu, yatim piatu, atau fakir miskin/dhuafa dengan memberikan kebutuhan primer seperti sandang, papan, pangan hingga kebutuhan kesehatan dan pendidikan (Pratama \& Indrawati, 2018). Panti Asuhan Muhammadiyah juga menjadi lembaga pendidikan non formal, karena pendidikan agama dan pedidikan akhlak selalu ditanamkan kepada anak-anak yang tinggal di dalamnya (Sulthoni \& Sarmini, 2013).

Salah satu panti asuhan milik Muhammadiyah yang berada di Kabupaten Kulon Progo Daerah Istimewa Yogyakarta adalah Panti Asuhan (PA) Muhammadiyah Ahmad Sudjari yang berdiri pada tanggal 6 Maret 2008. PA ini tepatnya terletak di RT 91 RW 22, Dusun 
Jonggrangan, Desa Jatimulyo, Kecamatan Girimulyo. Sejak berdiri hingga tahun 2012 kondisi prasarana PA tersebut masih sangat sederhana. Dinding setiap ruang menggunakan papan tripleks dan lantai dari konblok. Dengan menggunakan dana yang terkumpul sedikit demi sedikit dari para donatur, maka pada tahun 2013 ruang tidur untuk santri putri sudah bisa dibangun dengan menggunakan dinding batu bata dan lantai keramik, sedangkan kamar untuk para santri putra masih menggunakan ruang yang lama. Saat ini ada 20 santri (8 putri dan 12 putra) dari berbagai daerah dengan tingkat pendidikan dan usia yang berbeda, mulai dari usia 12 hingga 15 tahun yang tinggal di PA tersebut. Mereka menempati 3 kamar untuk santri putra dan 2 kamar untuk santri putri, masing-masing seluas 2,5 × $3 \mathrm{~m}^{2}$, serta 2 kamar mandi. Kondisi bangunan dapat dilihat pada Gambar 1.

Beberapa permasalahan prasarana fisik yang dihadapi pengurus PA Muhammadiyah Ahmad Sudjari adalah:

1. Ruang-ruang yang sudah ada kondisinya masih sangat sederhana dan kurang representatif.

2. Perlu adanya tambahan ruang tidur dan kamar mandi/WC untuk menampung anak yang jumlahnya semakin bertambah.

3. Perlu adanya tambahan ruang yang akan difungsikan untuk ruang tamu, ruang kantor, dapur dan ruang bersama.

Pihak pengurus PA Muhammadiyah Ahmad Sudjari bersama dengan Pimpinan Cabang Muhammadiyah Girimulyo sudah lama menginginkan untuk merenovasi dan memperluas bangunan agar menjadi tempat tinggal dan tempat belajar agama bagi santri yang representatif dari segi keamanan dan kenyamanan. Akan tetapi terdapat beberapa kendala yang dihadapi, yaitu kurangnya kemampuan untuk merancang bangunan yang memenuhi standar struktur, serta ketidakmampuan dalam membiayai pembangunan tersebut secara mandiri. Hal ini dikarenakan minimnya dana yang dimiliki oleh pihak PA Muhammadiyah Ahmad Sudjari. Untuk itu tim Pengabdian kepada Masyarakat (PkM) dari Program Studi Teknik Sipil Universitas Muhammadiyah Yogyakarta (UMY) yang terdiri dari dosen dan mahasiswa melakukan kegiatan pengabdian di tempat tersebut dengan tujuan untuk membantu mewujudkan bangunan yang lebih aman dan nyaman dengan biaya yang terjangkau.

\section{METODE PELAKSANAAN}

Kegiatan PkM yang dilaksanakan selama 6 bulan ini meliputi beberapa tahap, yaitu:

1. Tahap pendahuluan

Dalam merancang suatu struktur, fungsi bangunan dan kondisi lingkungan sangat berpengaruh terhadap letak bangunan permanen yang direncanakan. Oleh karena itu, sebelum melaksanakan pekerjaan perancangan struktur terlebih dahulu dilakukan beberapa tahapan pendahuluan:

a. Pertemuan antara pengurus PA Muhammadiyah Ahmad Sudjari dengan tim PkM Prodi Teknik Sipil UMY untuk memperoleh masukan tentang rancangan bangunan dan pembagian ruang yang diinginkan (Gambar 2).

b. Melakukan survei lokasi dengan tujuan:

1) untuk mengetahui secara pasti situasi lokasi yang akan dibangun, sehingga dapat diketahui batas-batas lahan yang akan digunakan.

2) untuk mengukur luas lahan yang tersedia.

3) untuk menentukan bentuk arsitektur bangunan, sehingga didapat bentuk bangunan yang serasi dengan lingkungan.

c. Melakukan survei topografi untuk menentukan elevasi lantai bangunan, penempatan sumur resapan dan jaringan drainasi.

2. Tahap perancangan struktur

Perancangan struktur adalah proses penentuan dan perhitungan dimensi bagian-bagian struktur dari suatu bangunan agar struktur yang direncanakan mampu mendukung semua beban yang bekerja. Perancangan struktur bertujuan untuk menghasilkan suatu struktur yang stabil, kuat, awet, ekonomis dan kemudahan pelaksanaan. Suatu struktur dikatakan stabil jika tidak mudah terguling, tergeser atau miring selama umur bangunan yang direncanakan 
(Tumewu, Saerang, \& Harahap, 2019). Dengan demikian diharapkan struktur tersebut aman, nyaman, dan tidak menimbulkan dampak di lingkungan sekitar. Dasar perancangan dan analisis hitungan harus mengikuti peraturan yang berlaku di Indonesia, sehingga kualitas struktur dapat dipertanggungjawabkan. Adapun standar perancangan yang digunakan adalah:

a. SNI 1726:2012 tentang Tata Cara Perencanaan Ketahanan Gempa untuk Struktur Bangunan Gedung dan Non Gedung (Badan Standardisasi Nasional, 2012).

b. SNI 1727:2013 tentang Beban Minimum untuk Perancangan Bangunan Gedung \& Struktur Lain (Badan Standardisasi Nasional, 2013).

c. SNI 2847:2013 tentang Persyaratan Beton Struktural untuk Bangunan Gedung (Badan Standardisasi Indonesia, 2013).

Proses selanjutnya adalah perhitungan Rencana Anggaran Biaya (RAB), yaitu perhitungan besarnya biaya yang diperlukan untuk bahan dan upah, serta biaya-biaya lain yang berhubungan dengan pelaksanaan pembangunan (Isramaulana, 2016).

3. Tahap penyusunan proposal permohonan bantuan dana.

Biaya untuk mewujudkan bangunan tersebut diharapkan dari swadaya masyarakat dan para donatur. Karena dana yang terkumpul belum mencukupi, maka tim PkM Prodi Teknik Sipil UMY membantu menyusunkan proposal permohonan bantuan dana. Proposal kemudian disebarkan kepada masyarakat yang ingin menyalurkan infak dan shodaqohnya sehingga diharapkan pembangunan bisa segera terealisir.

4. Tahap pendampingan selama pelaksanaan pembangunan.

Seiring dengan pengumpulan dana, pembangunan mulai dilaksanakan. Proses pembangunan dilakukan secara gotong royong oleh warga masyarakat sekitar dengan dipimpin oleh beberapa warga yang sudah ahli, seperti yang dapat dilihat pada Gambar 3. Tim PkM Prodi Teknik Sipil UMY yang melibatkan mahasiswa melakukan pendampingan selama pelaksanaan pembangunan, sehingga diharapkan adanya proses pembelajaran dalam meningkatkan kompetensi lulusan Prodi Teknik Sipil UMY.

\section{HASIL}

Hasil yang dicapai pada program kegiatan pengabdian kepada masyarakat ini meliputi:

1. Dokumen hasil perancangan struktur seperti yang disajikan pada Gambar 4. Bangunan direncanakan dua lantai dengan ukuran 9,0x9,5 $\mathrm{m}^{2}$ per lantai.

2. Rencana Anggaran Biaya yang rekapannya disajikan pada Tabel 1. Biaya total yang dibutuhkan adalah sebesar Rp. 336.671.000,00 (tiga ratus tiga puluh enam juta enam ratus tujuh puluh satu ribu rupiah).

3. Dokumen proposal permohonan bantuan dana, yang kemudian bersama dokumen perancangan struktur diserahkan kepada pengurus PA Muhammadiyah Ahmad Sudjari (Gambar 5).

4. Bangunan gedung 2 lantai. Tim PkM memberikan pendampingan selama pembangunan hingga terwujud gedung 2 lantai dengan luas 9,0x9,5 $\mathrm{m}^{2}$ setiap lantainya. Adapun foto-foto hasil pembangunan dapat dilihat pada Gambar 6 dan Gambar 7.

\section{PEMBAHASAN}

Pada tahap perancangan, semula direncanakan akan dibangun gedung 1 lantai berukuran $9,0 \times 9,5 \mathrm{~m}^{2}$ yang terdiri dari ruang tamu $\left(3,5 \times 4,0 \mathrm{~m}^{2}\right)$, ruang kantor $\left(3,0 \times 2,5 \mathrm{~m}^{2}\right)$, ruang bebas $\left(3,0 \times 4,0 \mathrm{~m}^{2}\right)$, ruang tidur $\left(3,0 \times 3,0 \mathrm{~m}^{2}\right)$, dapur $\left(3,0 \times 3,5 \mathrm{~m}^{2}\right)$ dan ruang yang bisa difungsikan untuk ruang tidur jika santri jumlahnya bertambah $\left(6,5 \times 3,5 \mathrm{~m}^{2}\right)$. Dalam perkembangannya pihak pengurus PA Muhammadiyah Ahmad Sudjari memutuskan untuk mengubah rencana menjadi gedung 2 lantai, sehinggaTim PkM Prodi Teknik Sipil UMY melakukan revisi dari gambar rencana dan Rencana Anggaran Biaya yang telah dikerjakan.

Pada tahap penggalangan dana, tanggapan warga masyarakat sekitar dan para donatur sangat baik, sehingga dana pembangunan dapat terkumpul dan pembangunan bisa segera mulai dilaksanakan. Karena proses pembangunan dilakukan secara gotong royong oleh warga setempat, maka biaya tenaga dapat ditekan seminimal mungkin. Bahan bangunan juga dibeli 
dari toko material milik warga setempat, sehingga diperoleh harga yang bersaing dengan harga pasar. Selain itu, diperoleh kemudahan dalam pembayaran, sehingga pekerjaan tidak terhambat oleh bahan bangunan yang belum tersedia.

Pada tahap pelaksanaan pembangunan, bangunan lantai 1 dibuat sesuai dengan gambar rencana, tetapi untuk lantai 2 terdapat perubahan rancangan. Semula lantai 2 terdiri dari ruangruang seperti pada lantai 1 . Dengan mempertimbangkan dana yang tersedia dan kebutuhan ruang, maka pengurus PA Muhammadiyah Ahmad Sudjari memutuskan untuk menjadikan lantai 2 menjadi ruang pertemuan/aula. Sampai dengan berakhirnya kegiatan pengabdian kepada masyarakat ini pekerjaan yang belum dilaksanakan adalah pemasangan keramik lantai 1 , proses finishing (pengecatan) dan penambahan kamar mandi/WC.

\section{KESIMPULAN DAN SARAN}

Tim Pengabdian kepada Masyarakat (PkM) Prodi Teknik Sipil UMY telah melakukan kegiatan pengabdian di Panti Asuhan Muhammadiyah Ahmad Sudjari, Jonggrangan, Jatimulyo, Girimulyo, Kulon Progo, DIY. Kegiatan yang dilaksanakan meliputi proses perancangan struktur dan proses pelaksanaan pembangunannya. Dari kegiatan ini dihasilkan dokumen perancangan yang terdiri dari perhitungan struktur, desain gambar gedung dua lantai dan Rencana Anggaran Biayanya. Tim PkM juga memberikan pendampingan selama pelaksanaan hingga proses pembangunan gedung 2 lantai dapat terlaksana secara bertahap sampai dengan pemasangan keramik lantai 2.

Kegiatan pengabdian kepada masyarakat ini diharapkan tetap dilanjutkan untuk memberikan bantuan pendampingan pembangunan hingga gedung 2 lantai dan kamar mandi/WC selesai $100 \%$.

\section{UCAPAN TERIMA KASIH}

Ucapan terima kasih disampaikan kepada:

1. Lembaga Penelitian, Publikasi, dan Pengabdian Masyarakat Universitas Muhammadiyah Yogyakarta (LP3M UMY) yang telah memberikan kesempatan dan mendanai kegiatan pengabdian kepada masyarakat ini sehingga kegiatan berjalan dengan lancar.

2. Pengurus Panti Asuhan Muhammadiyah Ahmad Sudjari, Dusun Jonggrangan, Desa Jatimulyo, Kecamatan Girimulyo atas kerjasama yang baik sehingga kegiatan pengabdian ini bisa terlaksana sesuai target.

3. Warga masyarakat Dusun Jonggrangan, Desa Jatimulyo, Kecamatan Girimulyo yang telah membantu selama pelaksanaan pembangunan.

4. Bapak Ir. M. Riang Endarto, MS yang telah memberikan sumbang saran dalam kegiatan pengabdian masyarakat ini.

\section{DAFTAR PUSTAKA}

Badan Standardisasi Indonesia. (2013). SNI 2847:2013, Persyaratan Beton Struktural untuk Bangunan Gedung. Jakarta: BSN.

Badan Standardisasi Nasional. (2012). SNI 1726:2012, Tata Cara Perencanaan Ketahanan Gempa Untuk Struktur Bangunan Gedung dan Non Gedung. Jakarta: BSN.

Badan Standardisasi Nasional. (2013). SNI 1727:2013, Beban Minimum Untuk Perancangan Bangunan Gedung dan Struktur Lain. Jakarta: BSN.

Isramaulana, A. (2016). Rencana Anggaran Biaya Untuk Sumur Resapan Masjid Besar Kota Banjarbaru. INFO-TEKNIK, 15(2), 239-254.

Pratama, J. A., \& Indrawati, I. (2018). Panti Asuhan Manzil AL-Ahlam Sebagai Lembaga Kesejahteraan Sosial Anak (LKSA) Yang Terfokus Minat dan Bakat Dengan Pendekatan Green Building. Universitas Muhammadiyah Surakarta.

Rusydi, R. (2016). Peran Muhammadiyah (Konsep Pendidikan, Usaha-Usaha di Bidang Pendidikan, dan Tokoh). TARBAWI: Jurnal Pendidikan Agama Islam, 1(2), 139-148. 
Sulthoni, Y., \& Sarmini. (2013). Strategi Pembentukan Karakter Anak di Panti Asuhan Muhammadiyah Wiyung Surabaya. Kajian Moral Dan Kewarganegaraan, 1(1), 272287.

Tahir, G. (2010). Muhammadiyah (Gerakan Sosial Keagamaan dan Pendidikan). Jurnal Adabiyah, 10(2), 160-169.

Tumewu, D., Saerang, E. J., \& Harahap, J. T. (2019). Studi Perbandingan Metode Perhitungan Struktur Statis Tak Tentu pada Portal Bangunan Gedung. Jurnal Teknik Sipil Terapan (JTST), 1(2), 1-10.

\section{LAMPIRAN}

kamar mandi untuk santri putra

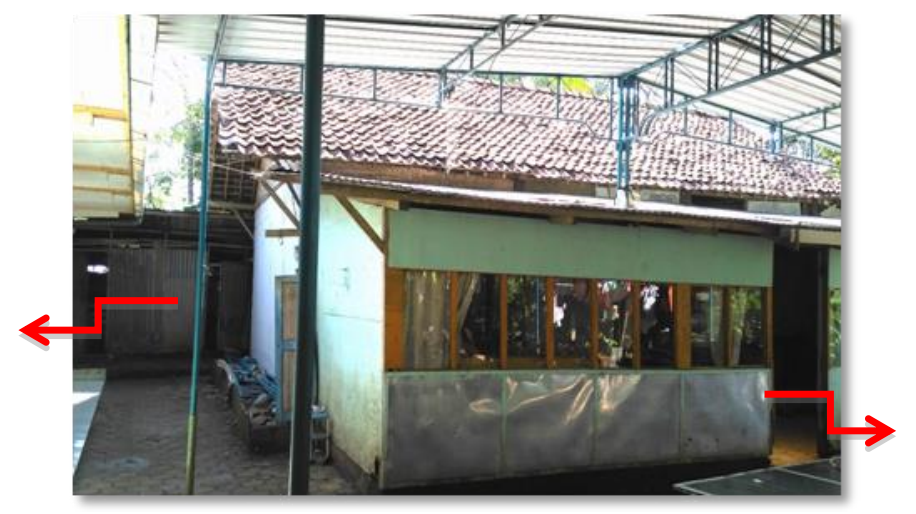

ruang tamu dan kamar untuk santri putra.

\section{Gambar 1. Bagian Depan Panti Asuhan Muhammadiyah Ahmad Sudjari}

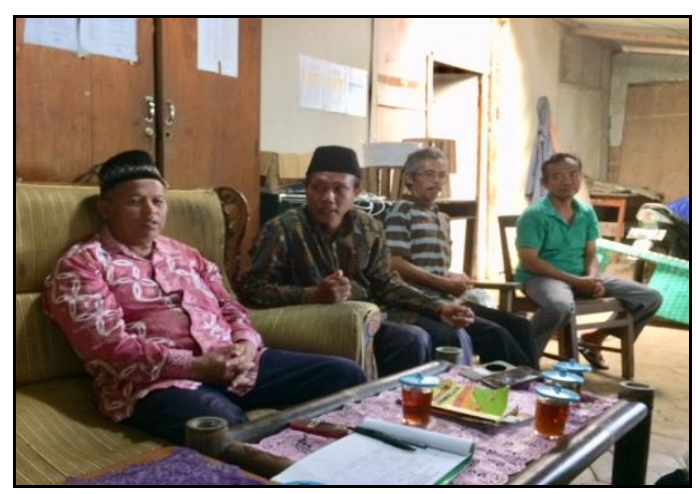

Gambar 2. Pertemuan dengan Pengurus PA Muhammadiyah Ahmad Sudjari 


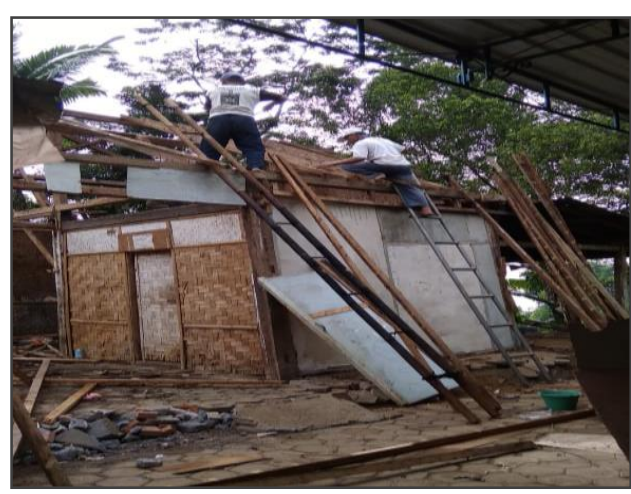

(a) Pembongkaran bangunan lama

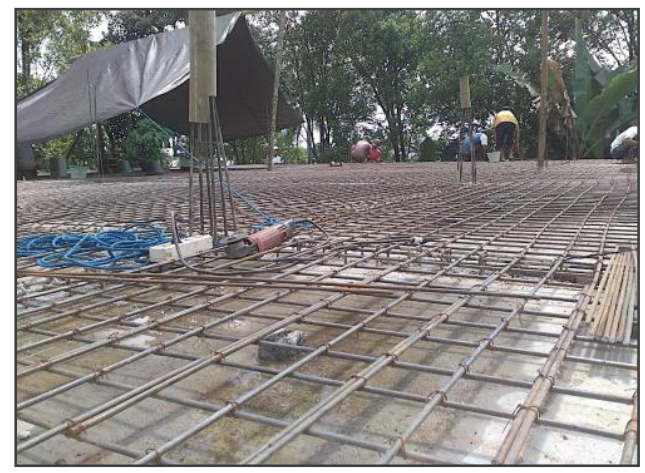

(c) Penulangan lantai atas.

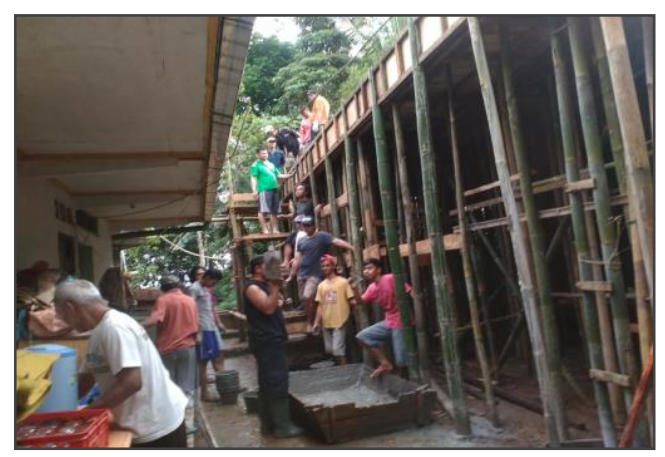

(e) pengecoran lantai atas.

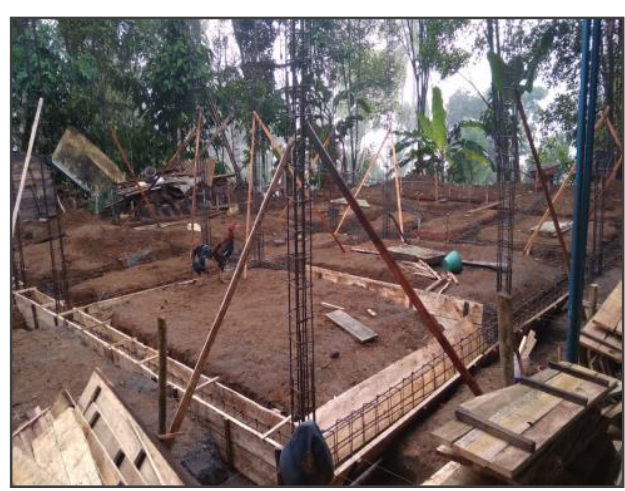

(b) Pembuatan fondasi.

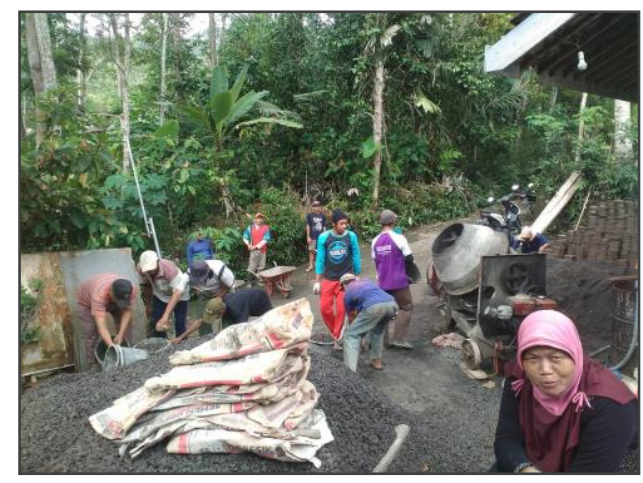

(d) Pengecoran lantai atas.

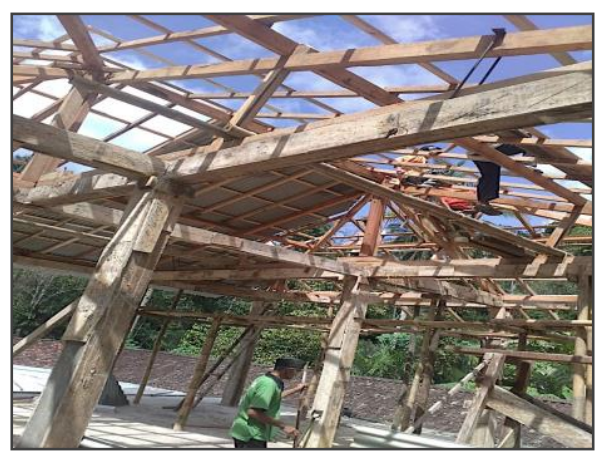

(f) Pemasangan atap lantai 2.

Gambar 3. Pelaksanaan pembangunan PA Muhammadiyah Ahmad Sudjari
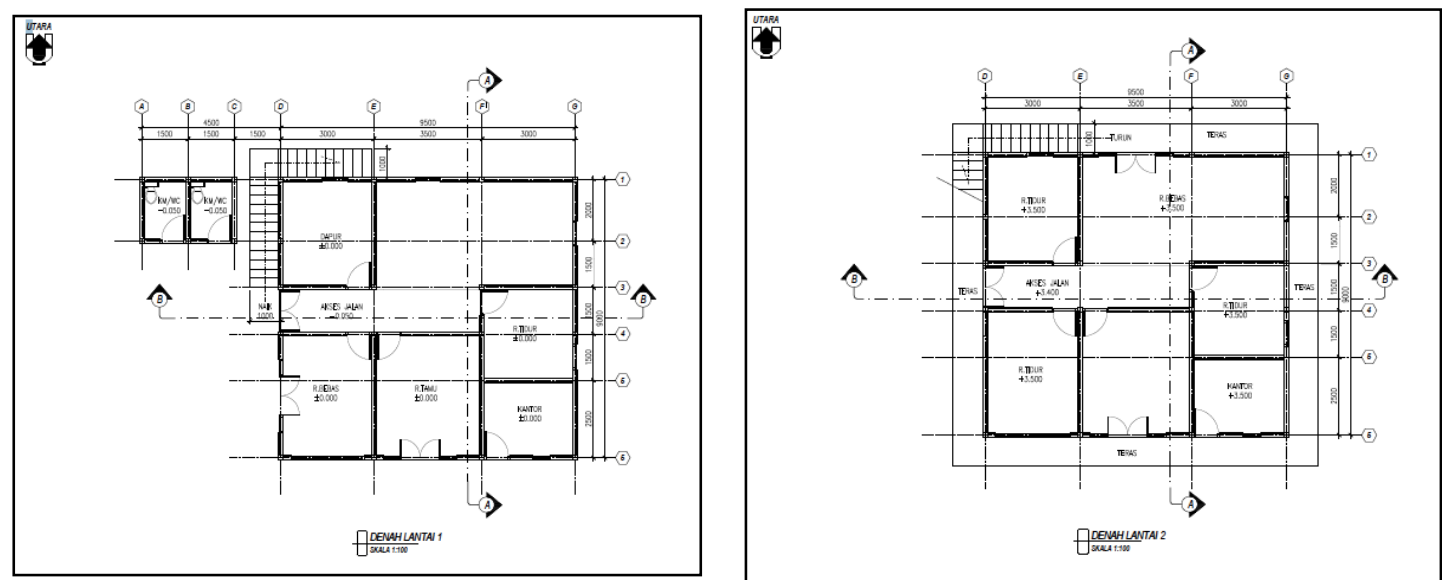
(a) Denah Lantai 1

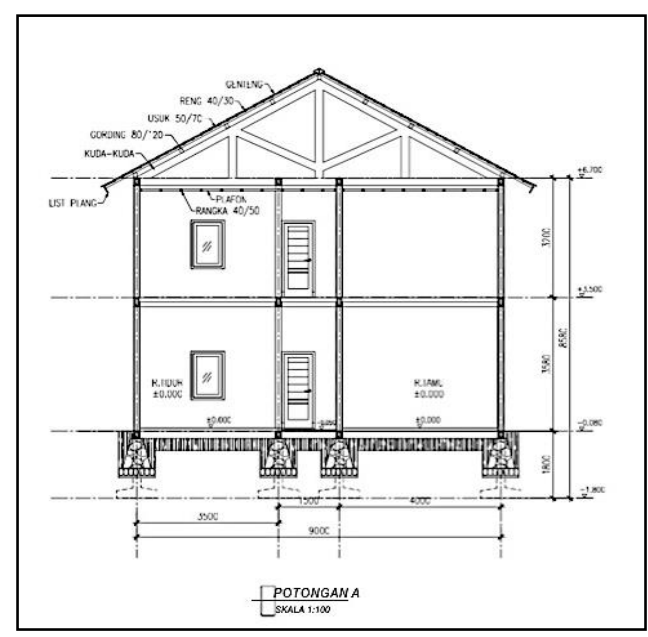

(c) Potongan A

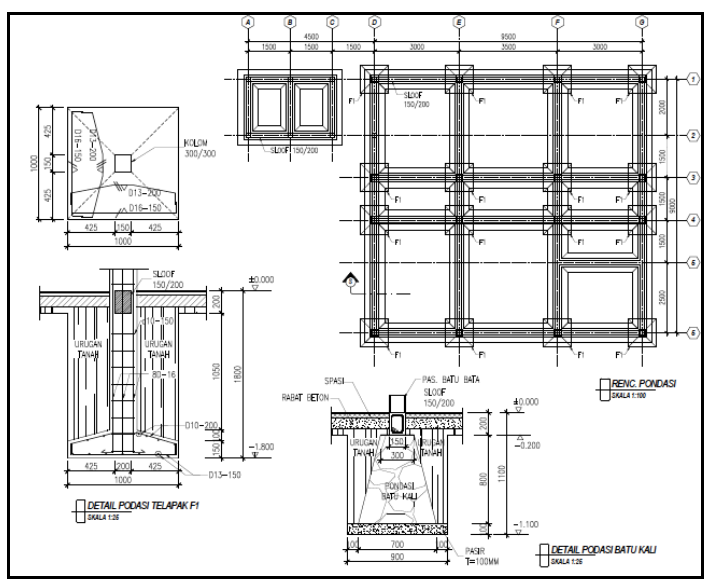

(e) Rencana Pondasi (b) Denah Lantai 2

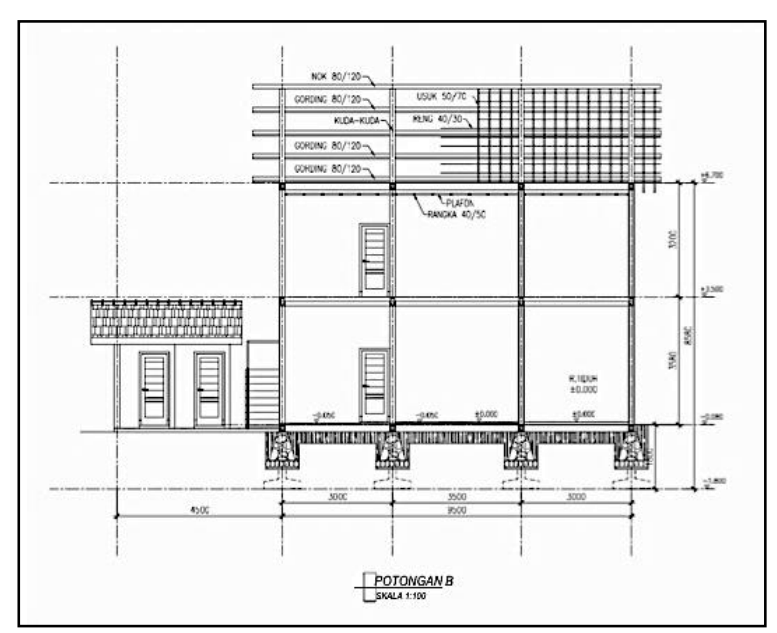

(d) Potongan B

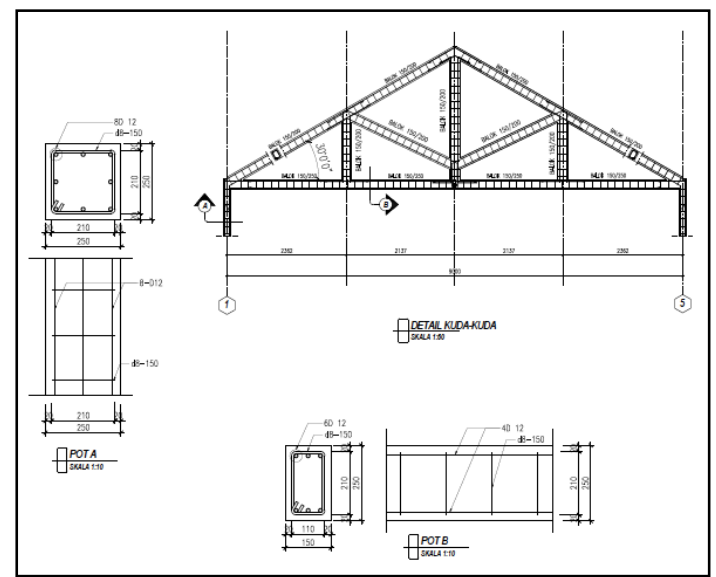

(f) Rencana Atap 


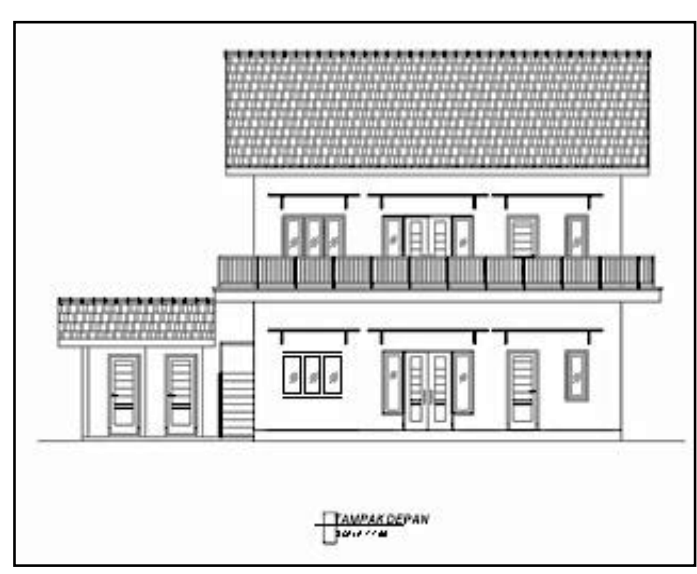

(g) Tampak depan

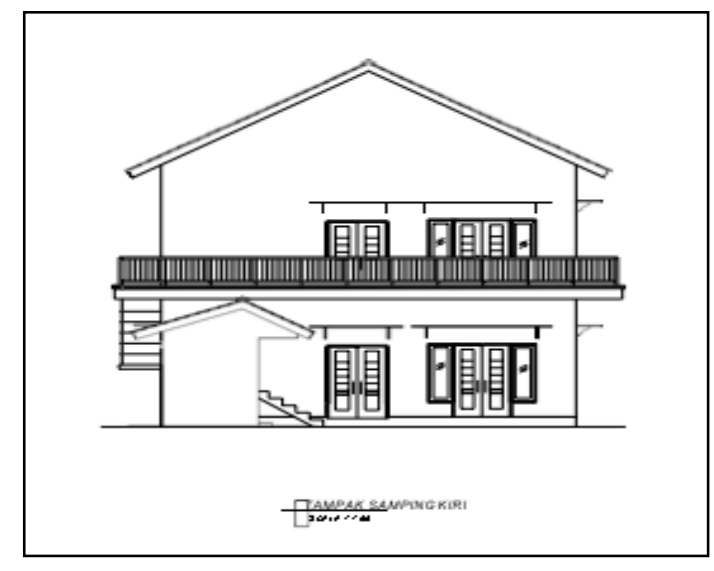

(h) Tampak samping kiri

\section{Gambar 4. Desain Gedung Panti Asuhan Muhammadiyah Ahmad Sudjari}

\section{Tabel 1. Rencana Anggaran Biaya Pembangunan Gedung Panti Asuhan Ahmad} Sudjari Girimulyo

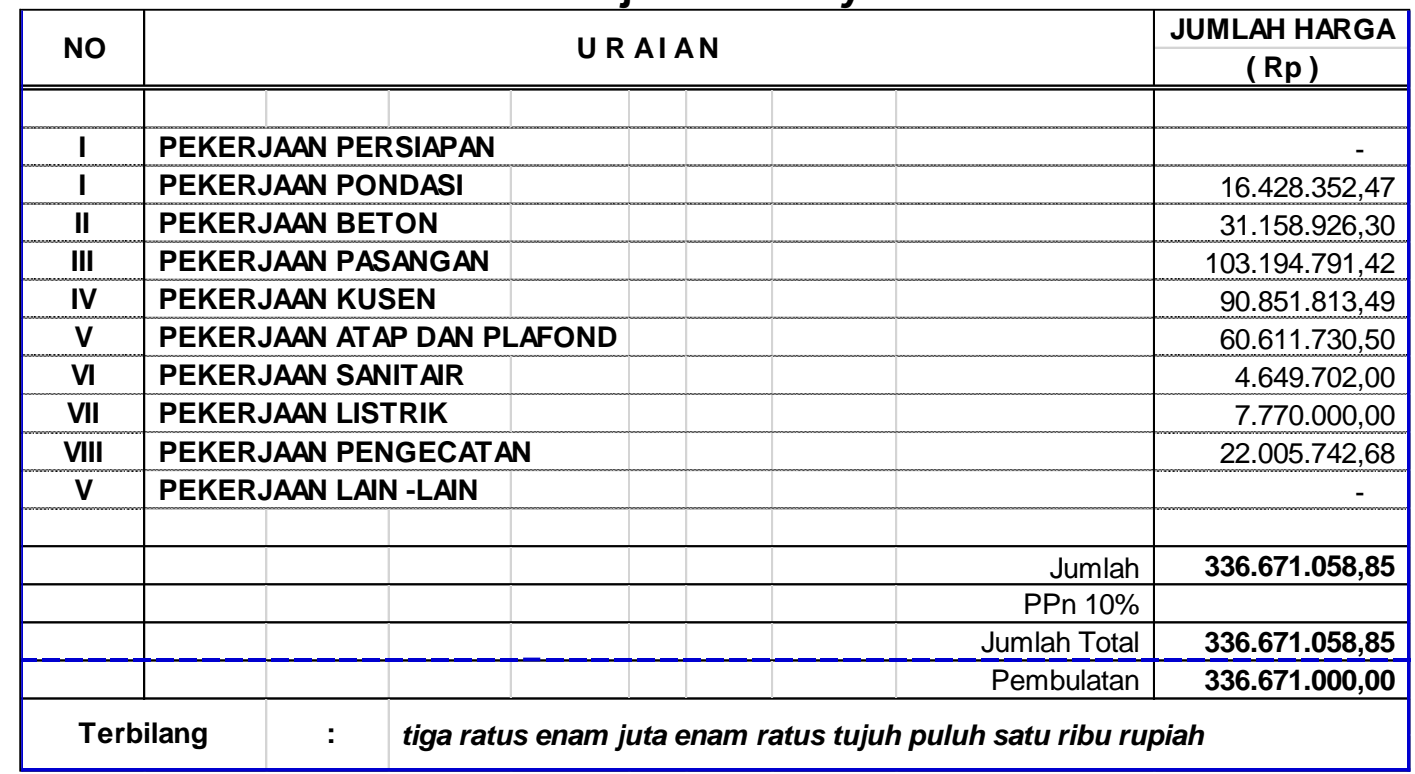

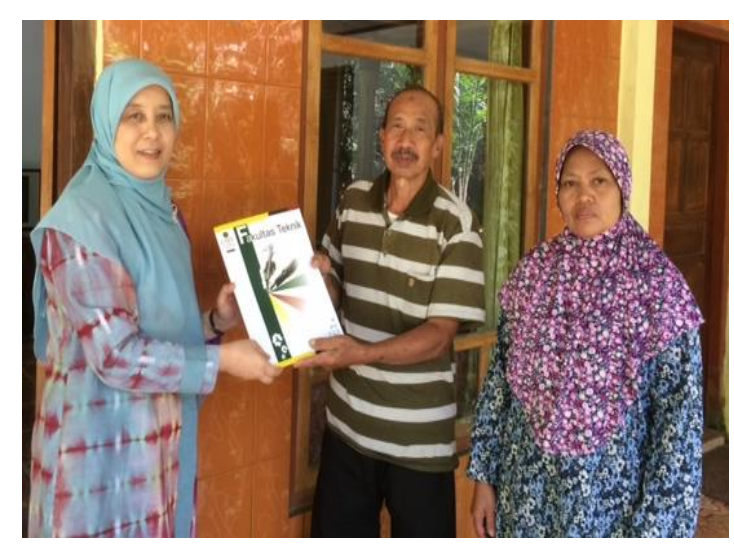

Gambar 5. Penyerahan dokumen perancangan struktur dan proposal bantuan dana 


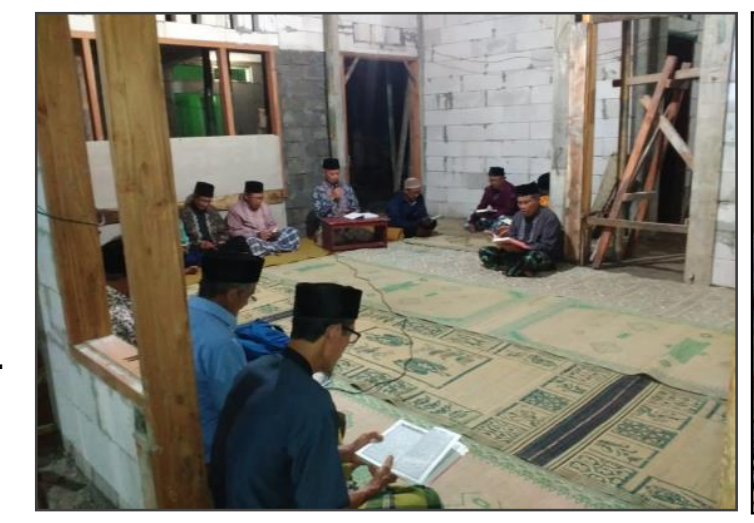

(a) Lantai dasar

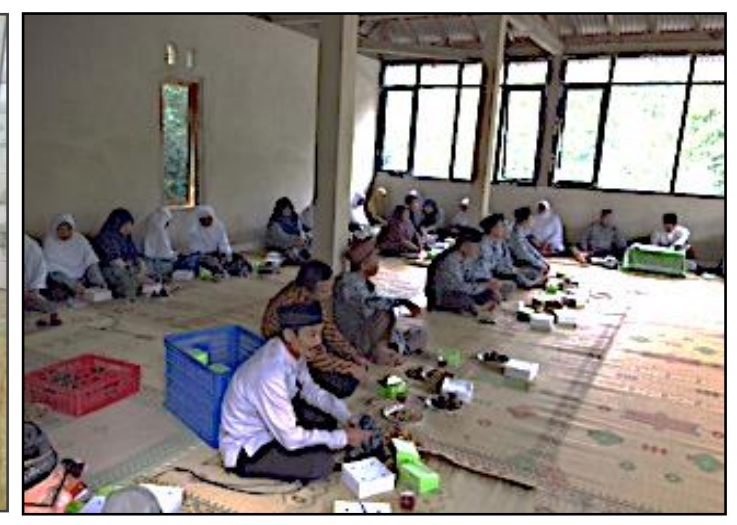

(b) Lantai atas

Gambar 6. Pengajian di lantai dasar dan atas

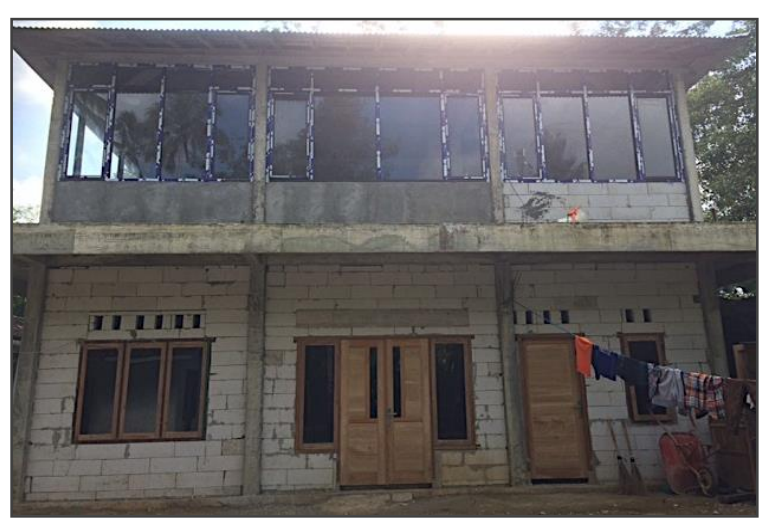

(a) Tampak depan

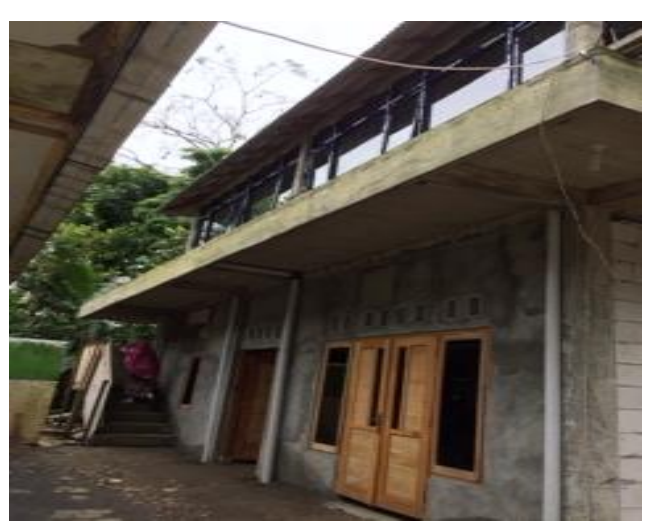

(b) Tampak samping kiri

Gambar 7. Gedung Panti Asuhan Muhammadiyah Ahmad Sudjari setelah direnovasi 